[ FAUSTO VIANA | ROSANE MUNIZ]

Fausto Viana é figurinista, cenógrafo e pesquisador. Professor livre-docente da ECA-USP.

E-mail: faustoviana@uol.com.br

Rosane Muniz é jornalista, atriz e autora do livro Vestindo os nus: o figurino em cena (Senac Rio, 2004). Mestra em Artes Cênicas (ECA-USP), mantém o blog www.vestindoacena.com.

E-mail: romuniz@gmail.com

\title{
Os figurinos em Bollywood
}

$[23]$

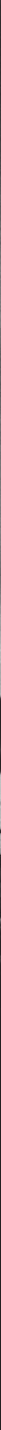


Bollywood é o apelido da indústria mais forte do cinema indiano. Ainda que não seja a única nem esteja restrita a apenas um local, o nome Bollywood tem sua origem a partir da cidade onde se concentra a indústria de cinema de língua hindi - Bombaim (atualmente chamada de Mumbai) - e Hollywood, distrito da cidade de Los Angeles, notável pela concentração mundial de empresas da área cinematográfica. Apesar de parecer que Bollywood é uma indústria nova, seguidora da prima americana, que se iniciou no começo do século $X X$, não é bem assim: o termo foi cunhado na década de 1970, quando a produção de filmes em Bollywood atingiu o recorde de maior produção mundial de títulos por ano.

A indústria é puramente comercial e o público adora, o que faz de Bollywood um sucesso. Claro, é necessário que haja consumo para que qualquer indústria continue existindo. Assim, apesar de toda a rigidez de análise dos scholars indianos, segundo 0 autor Shahab Ahmed', Bollywood prossegue. Em seu livro, Ahmed optou por publicar, quase sem texto, centenas de fotos para comprovar a história da indústria. Há uma imagem da primeira projeção cinematográfica na Índia, nos idos de 1890.

Analisando os trajes dos filmes, fica uma dúvida: é impressão ou a coisa muda muito pouco? E quando muda, incorpora o visual das produções norte-americanas para aumentar as vendas e concorrer com os filmes estrangeiros ao longo da história?

É fato que a roupa indiana é uma das mais importantes marcas da cultura do país. Ela pode definir a região, religião e origem das quais quem a usa provém. Muitos consideram o modo de vestir indiano uma forma de arte pela sua habilidade de adornar uma pessoa em vários aspectos: vestes, joias, ornamentos de cabeça, maquiagens... Por séculos, os tecidos indianos fascinaram pessoas do mundo inteiro e se tornaram famosos pela qualidade, variedade e maneira exótica de trabalhar os materiais.

Na moda indiana é possível conferir algumas variações ao longo das décadas. Resumindo, nos anos 1920, os trajes femininos ganharam cores no movimento pela igualdade dos sexos, e a tendência na alta sociedade foi fortemente influenciada pelos britânicos. Na década seguinte, as manifestações sociais trouxeram toques femininos e conservadores para as roupas. Foi quando a fundação do cinema indiano começou a se mostrar como forte influência na cena fashion. Nos anos 1940, as roupas são mais simples e funcionais, afinal é o período da II Guerra Mundial e da independência do país (1947). Em seguida, são abertas escolas de artes e aparecem diferenciações nos trabaIhos de formas e texturas das roupas, para que, nos anos 1960, materiais como filmes plásticos e poliéster comecem a surgir, até tornarem-se populares na década seguinte, quando a cultura disco modernizou um pouco a moda. Com a ascensão de designers americanos, como Calvin Klein, a década de 1980 masculinizou a silhueta e os salwar kameez ${ }^{2}$ passaram a ter ombreiras. Nos anos 1990, a mulher independente procurou o conforto em looks de poder e corporativos, mas, no século XXI, eis que a moda volta para o antigo, a fim de construir o novo e misturar todos os estilos e décadas.

É comum dizer que o Ocidente se inspira no Oriente, mas tanto na moda quanto no cinema vimos também o contrário. Da mesma forma que Hollywood "copia" o Egito, a Índia etc., Bollywood fez grandes números musicais da década de 1940 "copiados" da Broadway, entre outros. Importante dizer que a fundação dessa indústria remonta a 1913.

0 figurino como traje de cena, como "uma ferramenta externa, um apoio para a interpretação" ${ }^{\prime \prime}$ que surge no teatro da Rússia em fins do século XIX, influencia todo o mundo teatral (na mudança de "belo" para "útil" para o ator) e, posteriormente, o cinematográfico - só veremos começar a ser "pensado" em Bollywood mais de um século depois.

Priyanka Khanna ${ }^{4}$ conta que o tempo no qual o conceito de figurinista em Bollywood não existia já acabou. A figura discriminada de camareira, que separava roupas, foi substituída por profissionais do mais alto requinte, muitos vindos do mundo da moda. É o caso da figurinista Manish Malhotra, quando relata que, no início da carreira no cinema, a indústria costumava trabalhar com cinco vestidos para canções, três para cenas românticas, duas roupas para sequências com familias etc. E, "revolucionária", diz que começou a desenhar de acordo com as personagens, e não pelo número de roupas que elas deveriam ter. Essa "revolução" nos trajes de Bollywood começou na década de 1980. 


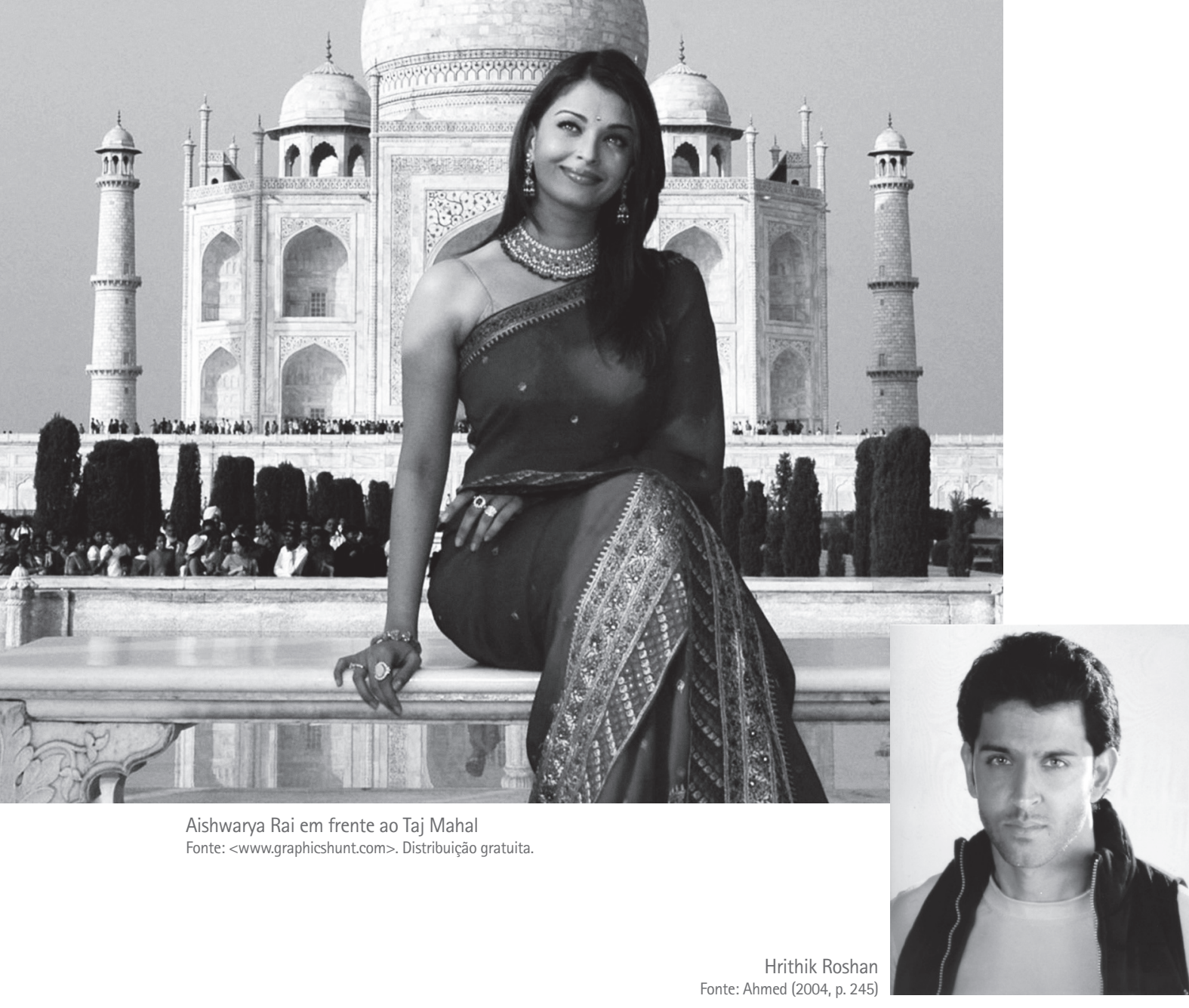

No filme Rangeela, Malhotra usou saias tão curtas que a indústria fashion percebeu que uma mudança tinha acontecido: o foco saiu do sonho para o realismo. Os temas passaram a ser contemporâneos, a indústria se interessou ao perceber o poder de venda, e os designers - como diz Khanna - não se importavam mais em ver seus nomes associados a Bollywood.

Então, é isso mesmo que você entendeu: Bollywood é para o povão, é para grandes massas, não é para ficar provocando grandes meditações, transes ou 0 que quer que tenha cunho filosófico. 0 objetivo principal é diversão. Os números musicais são coloridíssimos, cheios de gente cantando, dançando, namorando, flertando, enfim, o que o grande público gosta de ver. E isso inclui inúmeras trocas de roupas, cenas de batalha monumentais e, nos filmes épicos, lá vêm os elefantes, centenas de soldados e tudo o mais.

É o caso de Jodhaa Akbar, um épico de batalhas e... amor. Bem ao estilo do gosto popular, a protagonista é merecedora de todos os adjetivos que possam qualificar beleza: Aishwarya Rai. Foi modelo, Miss Mundo em 1994 e hoje é Embaixatriz Mundial da L'Oréal. E ela já é conhecida por aqui: esteve no longa Pantera Cor-de-Rosa 2 e no vídeo de Kajra Re, que fez parte da trilha sonora da novela Caminho das Índias, exibida pela TV Globo5 ${ }^{5} 0$ bonitão da história é Hrithik Roshan. Perceba nas fotos como eles são parecidos com o indiano comum que vai vê-los no cinema. Repare na cor da pele, dos olhos... São "indianos" típicos, não são? Os atores representam para o povo indiano exatamente aquilo que ele não consegue ser.

No mesmo artigo de Priyanka Khanna, a figurinista Neeta Lulla acrescenta que tudo foi muito bem pesquisado e que o projeto levou um ano e meio para ficar pronto, porque o período histórico (do Império Mogol, e não o Mongol, que tem a ver com Gêngis Khan) estava pouco documentado. Ela fez o desenho de todas as roupas e armaduras, confeccionadas em Jodhpur. A partir de suas sugestões, a empresa Tanishq criou as joias do filme, que contou também com as ideias do criador das armas Nitin Desai. Daí veio um dos principais ganchos comerciais ligados ao longa-metragem: uma coleção de joias Tanishq feitas de ouro, diamantes, rubis e jade.

Figurinista experiente de cinema e teatro, Lulla afirma querer desenhar para Demi Moore. Mas sabe que a possibilidade de a atriz ir para Bollywood é mínima. Faz questão de apontar que "há uma linha muito tênue entre sensualidade e vulgaridade. Como designer em filmes, eu sei que a heroína tem que parecer sexy, glamourosa e 
chamativa. Eu me mantenho nesses parâmetros, além dos quais eu comprometo minha ética". Lulla diz que para ela "a única diferença em desenhar para o palco e para a tela é que no primeiro as roupas são usadas por mais tempo"6.

Bollywood tem servido de inspiração para muita gente em termos de criação de trajes indianos. 0 diretor Baz Luhrmann declarou abertamente que Moulin Rouge foi inspirado nessa estética. Claro que não foram só os trajes indianos que levaram o filme a ganhar o Oscar de melhor figurino em 2001. E vale lembrar que uma indiana já recebeu o Oscar nessa mesma categoria: Bhanu Aitheya, pelo trabalho em Gandhi (1982), de Richard Attenbourgh.

\section{Enquanto isso, no Brasil...}

A novela Caminho das Índias, de autoria de Glória Perez, atingiu bons índices de audiência ao retratar parte da cultura indiana. Como não poderia deixar de ser, houve até uma gravação com cenas de Bollywood, para onde uma das personagens fugiu, rompendo com as tradições da família. A responsável pelo figurino do trabalho como um todo foi a figurinista e historiadora Emilia Duncan. Junto com os caracterizadores Marlene Moura e Rubens Libório, a equipe estudou todos os códigos das vestimentas hindus para adaptá-los à história da novela e esteve na Índia a fim de complementar a pesquisa.

Duncan diz que o desafio maior foi montar o guarda-roupa masculino, já que o feminino oferece muitos detalhes e opções - mais uma vez, Bollywood serviu de inspiração, bem como as publicações internacionais sobre moda.

A novela não faz frente ao mercado indiano de mil filmes por ano, pois acima de tudo trata-se de outro formato. Mas na opinião do diretor da trama, Marcos Schechtman, o significado da TV para os brasileiros é equivalente ao do cinema para os indianos.

Para continuar sonhando com o tema İndia, certamente não faltarão filmes mas é melhor começar logo, porque serão muitos packs de DVDs.

\footnotetext{
NOTAS

[1] AHMED, Shahab. Frames of fame: a visual voyage through Bollywood 1913-2004. Mumbai: Oasis, 2004. 0 livro está disponível para consulta no Consulado da İndia em São Paulo.

[2] 0 salwar kameez é muito usado pelas garotas e mulheres da região de Punjab. É composto de duas peças: uma túnica ou blusa (kameez) e uma calça ou peça de baixo (salwar). Usualmente, é utilizado com uma peça ao redor do pescoço (dupatta), de enorme variedade de cores e designs.

${ }^{[3]}$ Vide artigo de nossa autoria, 0 figurino teatral: a busca por unidade e raízes etnológicas, publicado em dObra[s], São Paulo, Estação das Letras e Cores, v. 3, n 5, p. 21-24, fev. 2008.

${ }^{[4]} 0$ artigo completo de Priyanka Khanna está disponível em: <www.realbollywood.com/news/2008/02/ bollywood-dress-designers.html>. Acesso em: 23 jul. 2009.

${ }^{[5]}$ Assista no blog www.vestindoacena.com (clique em dObra[s] na barra Categorias) ao curioso e engraçado clipe da música Chori Chori - também parte da trilha sonora da novela Caminho das Índias - em cena do filme 0 guru do sexo, uma tentativa de fazer um besteirol nos moldes do cinema de Bollywood, porém, em Hollywood. Depois ria dos absurdos da outra cena do filme que mistura dança indiana com o filme Grease. Veja também o trailler do filme Jodhaa Akbar.

${ }^{[6]}$ Disponivel em: <www.rediff.com/entertai/1999/sep/29neeta.htm>. Acesso em: 23 jul. 2009.
} 